Relations industrielles

Industrial Relations

\title{
Le Barreau de la Province et la législation ouvrière
}

Volume 10, numéro 3, juin 1955

URI : https://id.erudit.org/iderudit/1022704ar

DOI : https://doi.org/10.7202/1022704ar

Aller au sommaire du numéro

Éditeur(s)

Département des relations industrielles de l’Université Laval

ISSN

0034-379X (imprimé)

1703-8138 (numérique)

Découvrir la revue

Citer cet article

(1955). Le Barreau de la Province et la législation ouvrière. Relations

industrielles / Industrial Relations, 10(3), 199-199.

https://doi.org/10.7202/1022704ar

Tous droits réservés (C Département des relations industrielles de l’Université Laval, 1955
Ce document est protégé par la loi sur le droit d'auteur. L’utilisation des services d'Érudit (y compris la reproduction) est assujettie à sa politique d'utilisation que vous pouvez consulter en ligne.

https://apropos.erudit.org/fr/usagers/politique-dutilisation/ 
Pour entretenir lardeur qui, vous pousse à étudier ces problèmes et à en promouvoir les solutions, vous vous proposez, Messieurs, le noble but d'un service social indispensable à l'époque présente. Dans son domaine temporel, votre intention $s^{x}$ apparente a celle de lEglise, et de son divin Fondateur, dont la vie et la mort furent consacrés à lhumanité souffrante pour apporter un rémède à ses maux. S'il appartient au Christ seul de soulager tant de miseres et de servitudes qui pesent sur le genre humain en faisant luire lespoir de la rédemption, il faut aussi chercher en Lui la force intérieure, si nécessaire à qui s'inspire de son exemple et désire prolonger parmi les hommes d'aujourd'hui laction bienfaisante qui fut la sienne. Les commémorations solennelles de cette semaine suggéreront à la plupart d'entre vous, Nous en sommes sûr, les dispositions de l'âme, qui les soutiendront dans leur labeur souvent pénible et ingrat.

En gage des secours divins que Nous invoquons sur vous, sur vos familles, vos collaborateurs et tous ceux qui vous sont chers, Nous vous accordons de tout coeur Notre Bénédiction Apostolique.

\section{LE BARREAU DE LA PROVINCE ET LA LEGISLATION OUVRIERE}

\section{Lors du dernier Congrès général du Barreau de la Province, le Comité de législation outrière a adopté les résolutions suivantes:}

1. Qu'un appel des décisions de la Commission des accidents du travail soit établi de la manière suivante:

a) Sur les questions médicales, devant une commission médicale indépendante de la Commission;

b) Sur les questions de droit et sur les questions mixtes de droit et de fait, devant une commission administrative indépendante de la Commission;

c) Sur les décisions de cette commission administrative indépendante, devant un tribunal de droit commun

Que, lorsque lappel porte sur le montant de l'indemnité, le montant fixé par la Commission suit payé durant l'appel jusqu'à adjudication finale, sujet à des ajustements rétroactifs.

2. Que la Loi des relations ouvrières (S.R.Q., 1941, ch. 162A), soit amendée comme suit:

a) Promulguer un article $41 \mathrm{c}$ dans les termes suivants:

La Commission doit accorder audition publique à toute partie, patronale ou syndicale, qui lui soumet un litige.

b) Promulguer un article $41 \mathrm{~d}$ comme suit:

Les décisions de la Commission, de même que les dissidences d'un ou de plusieurs commissaires, doivent être motivées. Elles sont publiées chaque rnois par le ministre du Travail.

Que la Commission des relations ouvrières établisse le plus tôt possible des règles de procédures détaillées, précises et complètes. 